\title{
Consensus in bladder cancer research priorities between patients and healthcare professionals using a four-stage modified Delphi method
}

Agustina Bessa ${ }^{1}$, Steven Maclennan², Deborah Enting ${ }^{1,3}$, Richard Bryan ${ }^{4}$, Debra Josephs ${ }^{1,3}$, Simon Hughes ${ }^{1,5}$, Suzanne Amery ${ }^{6}$, Shamim Khan ${ }^{6}$, Sachin Malde ${ }^{6}$, Rajesh Nair ${ }^{6}$, Fidelma Cahill ${ }^{1}$, Harriet Wylie ${ }^{1}$, Ramesh Thurairaja $^{6}$, Kathryn Chatterton ${ }^{6}$, Netty Kinsella ${ }^{1,7}$, Christel Häggström ${ }^{8}$, Mieke Van Hemelrijck ${ }^{1}$

Affiliations:

1) King's College London, School of Cancer and Pharmaceutical Studies, Translational Oncology \& Urology Research (TOUR), London, UK

2) Academic Urology Unit, University of Aberdeen, Aberdeen, UK

3) Guy's and St Thomas' NHS Foundation Trust, Dept of Medical Oncology, London, UK

4) Institute of Cancer \& Genomic Sciences, University of Birmingham, UK

5) Guy's and St Thomas' NHS Foundation Trust, Dept of Clinical Oncology, London, UK

6) Guy's and St Thomas' NHS Foundation Trust, Dept of Urology, London, UK

7) Royal Marsden NHS Foundation Trust, London, UK

8) Department of Surgical Sciences, Uppsala University, Uppsala, Sweden Department of Biobank Research, Umeå University, Umeå, Sweden

Corresponding author: Agustina Bessa (Agustina.bessa@kcl.ac.uk), TOUR team, Guy's Hospital, $3^{\text {rd }}$ Floor Bermondsey Wing, London SE1 9RT, UK

Email addresses of co-authors: steven.maclennan@abdn.ac.uk; deborah.enting@kcl.ac.uk;

R.T.Bryan@bham.ac.uk; debra.josephs@kcl.ac.uk; simon.1.hughes@kcl.ac.uk; Suzanne.Amery@gstt.nhs.uk; shamimatguys@gmail.com; Sachin.Malde@gstt.nhs.uk; Rajesh.Nair1@gstt.nhs.uk;

Fidelma.Cahill@gstt.nhs.uk; Harriet.Wylie@gstt.nhs.uk; Ramesh.Thurairaja@gstt.nhs.uk;

Kathryn.Chatterton@gstt.nhs.uk; netty.kinsella@rmh.nhs.uk; netty.kinsella@rmh.nhs.uk;

mieke.vanhemelrijck@kcl.ac.uk

Word count: 773 / 800

Key words: Bladder cancer, priority research questions, patients, healthcare professionals, Delphi-method 
Acknowledgements: We would like to thank the British Association of Urological Surgeons, British UroOncology Group, Action Bladder Cancer UK and Fight Bladder Cancer for their participation in this work. We also like to thank the Dianne and Graham Roberts Charitable Settlement for their support of the TOUR team.

Outcomes in bladder cancer $(\mathrm{BC})$ have not improved over the last 25 years and there are many unanswered research questions (1). Patient and public involvement (PPI) has not yet been explored to prioritise the relatively small amount of funding that $B C$ attracts (2). This study aimed to identify and prioritise $B C$ research questions, in collaboration with PPI representatives and healthcare professionals (HCPs), to ensure that future funding can be invested in the most strategic way.

We applied a four-stage modified Delphi method in a PPI setting (2): 1) systematic review of unanswered research questions proposed in BC randomised controlled trials (RCTs) and clinical practice guidelines (CPGs); 2) two focus groups with key stakeholders (patients and HCPs); 3) two-round Delphi survey sampled for breadth of opinion in clinical expertise and disease; 4) one consensus meeting with both stakeholders groups (See supplementary material for methodology description ).

The systematic literature review identified 41 unanswered research questions which were used as a basis for the focus groups (See supplementary material for flow diagram of identified unanswered research questions). Ten patients ( $80 \%$ males and $20 \%$ female) distributed between high and low risk BC (50\% and $40 \%$ high risk BC, respectively and $10 \%$ unsure) participated in a focus group conducted by a PPI coordinator. Six HCPs (2 medical oncologists, 1 radiation oncologist, 1 urology nurse specialist, 2 urological surgeons) participated in the second focus group and confirmed the uncertainty of the research questions. Both focus groups also confirmed that the interests and needs of both patients and HCPs were covered by the proposed unanswered research questions. The final 41 unanswered research questions were translated into both lay and clinical versions for use in the prioritisation survey (see supplementary information).

Sixty-eight patients and 48 HCPs participated in the first round. A second round of the survey was released including nine new questions, which were suggested by participants in the first round. Thirty patients and 32 HCPs participated in the second round of the survey. The demographics of the participants in both rounds of 
both surveys were well-balanced. The results of the two Delphi rounds were compared to identify the top 10 research questions from patients and HCPs. Seventy percent of the top 10 research questions were the same for both rounds in patients, and $30 \%$ of the top 10 research questions were the same in both rounds for HCPs. A comparison of the list of top 10 research questions was made and it was concluded that $70 \%$ of the questions from both stakeholder groups were concordant. The 10 research questions concordant between both stakeholder groups and with higher score were taken to a consensus meeting involving 7 stakeholders to cover the width of expertise ( 2 medical oncologists, 1 radiation oncologist, 1 urology nurse specialist, 2 urological surgeons and 1 patient advocate) and resulted in the ranking of the top $10 \mathrm{BC}$ research priorities (Table 1). Three research themes emerged: prognostic and predictive biomarkers, improved diagnostic techniques for accurate staging, and surveillance following radical therapy.

The recently announced top 10 research priorities for patients living with and beyond cancer from NCRI are clearly aligned with the three themes identified here (3). Our top $10 \mathrm{BC}$ research priorities identified by patients and HCPs (Table 1) are supported by the current literature (4). The appropriate management of BC patients relies heavily upon risk stratification to personalise therapy for the patient. Not all BCs are the same and therefore molecular profiling with appropriate biomarkers will help systematic treatment selection and risk stratification, which is an important tool for achieving optimal patient outcomes whilst avoiding overtreatment (4). There are some other patient's involvement studies that define research priorities for BC where the main themes defined are concordant to our findings (5). Our study adds a strong and transparent alignment between patients and HCPs needs.

This PPI initiative to prioritise research questions for BC made all efforts to involve patients and HCPs throughout; we conducted two rounds of the Delphi survey and collaborated with additional key stakeholders (patients, charities and healthcare professionals) to ensure breadth of opinion. We encountered some challenges throughout this process. The language used in communicating with key stakeholders (focus groups and surveys) required several iterations to minimise confusion and discomfort. Moreover, it is not possible to be $100 \%$ sure about the generalisability of our findings as participation in the Delphi survey was voluntary through social media and therefore self-selecting. However, patient demographics were similar between both rounds and findings for patients and HCPs were consistent across both survey rounds. 
In conclusion, by involving HCPs who manage $\mathrm{BC}$ and patients who have experienced $\mathrm{BC}$ and its treatments, our findings have highlighted and prioritised clinically relevant research questions in a transparent way. As key stakeholders in this setting, it is imperative that both patients and HCPs co-create the research agenda. 
Table 1: Top 10 unanswered research questions for BC

\begin{tabular}{|c|l|}
\hline Ranking & Research question \\
\hline $\mathbf{1}$ & $\begin{array}{l}\text { Could molecular profiling of MIBC help select and stratify patients for treatments in respect to } \\
\text { risk of relapse and/or prognosis? }\end{array}$ \\
\hline $\mathbf{2}$ & $\begin{array}{l}\text { Which prognostic biomarkers are useful in patients with high-risk NMIBC and MIBC to select } \\
\text { effective radical treatments? }\end{array}$ \\
\hline $\mathbf{3}$ & Can new genomic markers help us risk stratify patients and predict response to therapies? \\
\hline $\mathbf{4}$ & Which biomarkers would allow us to better select high-risk NMIBC patients for early cystectomy? \\
\hline $\mathbf{5}$ & Can new urinary and/or serum-based markers replace invasive techniques in the diagnosis of BC? \\
\hline $\mathbf{6}$ & $\begin{array}{l}\text { Can new validated technologies improve the detection of metastatic disease in regional } \\
\text { lymphatics and distant sites? }\end{array}$ \\
\hline $\mathbf{7}$ & $\begin{array}{l}\text { Can new urinary and/or serum-based markers improve the detection of BC recurrence post } \\
\text { treatment and/or detection of metastatic BC? }\end{array}$ \\
\hline $\mathbf{8}$ & $\begin{array}{l}\text { What PET imaging agent/tracer would increase the sensitivity and specificity of metastatic BC } \\
\text { detection? }\end{array}$ \\
\hline $\mathbf{9}$ & Following definitive treatment for MIBC, what is the optimal strategy for surveillance? \\
\hline $\mathbf{1 0}$ & What is the consequence of delay between TURBT and definitive treatment? \\
\hline
\end{tabular}


1. Boormans JL, Zwarthoff EC. Limited Funds for Bladder Cancer Research and What Can We Do About It. Bladder cancer (Amsterdam, Netherlands). 2016;2(1):49-51.

2. National Institute for Health and Research (NIHR). Patient and public involvement in health and social care research: A handbook for researchers. 2014.

3. Li F LI, Morgan A, McCullagh A, Johnson A, Giles C, Greenfield D, Crawford G, Gath J, Lyons J, Andreyev J, Tobutt J, Tugwell J, Robb K, Cove-Smith L, Bennister L, Doyle N, Lee N, Nash R, Simcock R, Stephens R, Best S, Griffiths S, Moug S, Regan S, Ellis $P$, editor Living with and beyond cancer top research priorities in the UK - priority setting partnership. National Cancer Research Institute Cancer Conference; 2018; Glasgow, UK.

4. Matulay JT, Kamat AM. Advances in risk stratification of bladder cancer to guide personalized medicine [version 1; referees: 4 approved]. F1000Res. 2018;7.

5. Angela B. Smith, Stephanie Chisolm, Allison Deal, Alejandra Spangler, Diane Z. Quale, Rick Bangs, J. Michael Jones, John L. Gore, Patient-Centered Prioritization of Bladder Cancer Research. 10.1002/cncr.31530 


\section{Supplementary material - METHODOLOGY}

We applied a four-stage modified Delphi method in a patient and public involvement (PPI) setting (7): 1) systematic review of unanswered research questions proposed in BC randomised controlled trials (RCTs) and clinical practice guidelines (CPGs); 2) two focus groups with key stakeholder groups (patients and HCPs); 3) a two-round Delphi survey for breadth of opinion in clinical expertise and disease; 4) one consensus meeting with both stakeholders groups.

\section{Stage 1: Systematic literature review}

The systematic review was performed in accordance with the PRISMA statement. The aim was to identify unanswered research questions regarding diagnosis, treatments and surveillance for BC. We included international CPGs and RCTs of BC interventions. These sources were targeted because they are the most likely places to find research uncertainties. European, American and NICE CPGs were selected in order to gather worldwide coverage of uncertainties as well as specific of the area were focus groups were conducted. Evidence gaps in CPGs are clearly highlighted as future research needs and uncertainties and these were manually identified. Primary RCTs were identified using a structured search strategy to identify BC effectiveness RCTs. We restricted the search to the most recent 10 years (May 2008 - May 2018) as a pragmatic way to focus on current uncertainties and uncertainties related to the trial itself were excluded. We also searched Twitter and patient support forums from advocacy groups including Action Bladder Cancer UK and Fight Bladder Cancer through the previous year. The search was made through online posts and comments to gather the themes discussed by patients and patient's representatives. Pubmed was also searched for reviews in $\mathrm{BC}$ for the most recent 10 years. Figure 1 represents the flow diagram of identified unanswered research questions and there was no exclusion of uncertainties. Data were extracted on any aspect of uncertainty identified in the various sources. After screening uncertainties were treated and translated into unanswered research questions using the PICO (population, intervention, comparison and outcomes) framework to create the first draft of unanswered research questions. Duplicates or uncertainties for which information was not available to create a research question were excluded. These questions were grouped into three categories: patient satisfaction, diagnostics and treatments. 
Two semi-structured focus groups were conducted to explore patients and HCPs perspectives and to triangulate with the unanswered research questions identified in stage 1.

\section{Focus groups with HCPS}

Healthcare professionals were recruited from Guy's Hospital (London). We aimed to cover the breadth of relevant clinical experience and thereby included medical oncologists, radiation oncologists, urological surgeons and clinical nurse specialists. Upon consent for participation, participants were asked to read the draft survey of unanswered questions (stage 1). They confirmed the uncertainty of the proposed questions from stage 1 as well as improved the clinical language for clarity.

\section{Focus group with patients}

Participants were recruited through BC support groups and using social media (Twitter/Facebook pages of Fight Bladder Cancer and Action Bladder Cancer UK) during a time frame of four weeks. This sample aimed to reflect both genders, breadth of experience of people who have bladder cancer, and the harms and benefits of treatment. An introduction to the project was presented and upon providing consent for participation, patients were then asked to rank the unanswered research questions. Different aspects related to overall patient satisfaction (diagnostic process, psychological support, information given, level of specialisation of HCPs, follow-up timing, treatment and diagnostic techniques and cost) were ranked in terms of their importance (most important, second most important, least important). The ranking exercise was followed by a guided discussion covering all the aspects of potential unanswered research questions for BC. All participants were provided with time and opportunity to share any other relevant information. They also provided feedback on the lay language used to phrase the questions and instructions for the Delphi prioritisation process, such as mention of high and low risk bladder cancer for comfort of patients (stage 3).

\section{Stage 3: Two-round Delphi prioritisation process}

We conducted a two-round modified Delphi prioritisation survey. The HCP survey was distributed with the assistance of the British Association of Urological Surgeons and the British Uro-Oncology Group (Table S1). The survey for patients and their family/friends was distributed with the help of Action Bladder Cancer UK and Fight Bladder Cancer (Table S2). Both surveys were also advertised through Twitter and Facebook. Hence, all 
participants voluntarily chose to participate in the survey as part of our aim to involve patients and public in identifying the most important unanswered research questions for BC. Participants were asked to score each unanswered question on a scale from 1 (not important) to 9 (critically important). Questions were blockrandomised to avoid participants' attention spans influencing the scoring of the surveys. The surveys were anonymous. However, demographic information was collected: patients were asked to provide their age, gender and cancer type (low or high-risk BC). To facilitate understanding, ease of language and patient's comfort, patients were not required to know if their cancer was invasive, metastatic or non-invasive. Family members or friends of patients with $\mathrm{BC}$ were asked to report this information based on the $\mathrm{BC}$ patient that they knew. HCPs were asked to provide their age, gender and profession. The first round of the questionnaire allowed participants to add further questions as free text. Hence, the second round included nine additional unanswered questions. Participants were also asked if they had participated in the first round. The first version of the survey was live for two weeks, after which a second version was launched and available for four weeks. The 10 highest scored questions ( $>70 \%$ of participants indicated a score of $\geq 7$ ) for the first and second round within each stakeholder group were compared and listed. Those questions were then compared between both groups and the concordant ones were selected for the consensus meeting (stage 4).

\section{Stage 4: Consensus meeting}

Several stakeholders (radiation oncologists, medical oncologists, urological surgeons, nurse specialists and patient and public involvement specialists) were invited to participate in a face-to-face consensus meeting held on 19th October 2018. The meeting specifically aimed to contain expertise from different specialities and patient's perspective. Based on the nominal group technique (NGT), which is a highly structured face-to-face group interaction, to empower participants to provide an opportunity to share their opinions to other members, stakeholders were requested to rank the 10 highest scored research questions from 1 (most important) to 10 (least important) and provide their respective reasoning. An independent expert in consensus methods moderated the meeting ensuring all participants were encouraged to provide their opinion. The objective of the meeting was to agree on the highest research priority themes as to inform the most strategic way to conduct future $\mathrm{BC}$ research. 
Figure 1. Systematic review flow diagram of identified uncertainties in $B C$ research

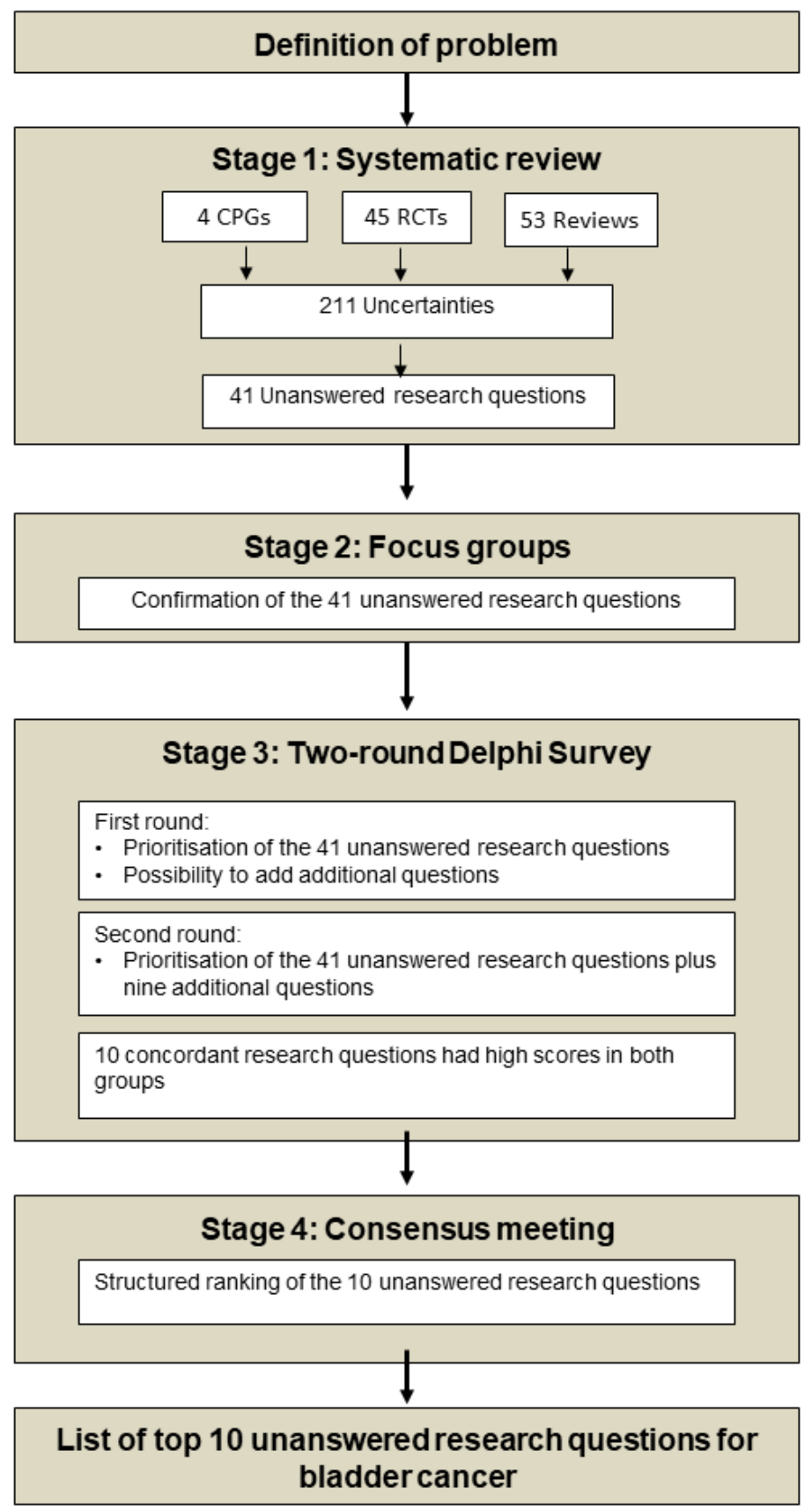

CPGs: Clinical practice guidelines; RCTs: Randomized clinical trials; 
Table S1. Technical version of the unanswered research questions used in the $1^{\text {st }}$ and $2^{\text {nd }}$ round of survey for HCPs.

\begin{tabular}{|c|c|}
\hline Round 1 & \\
\hline Number & Unanswered research questions \\
\hline 1 & $\begin{array}{l}\text { Is patient satisfaction of bladder cancer (BCa) low due to invasive investigations and/or } \\
\text { treatment follow-up? }\end{array}$ \\
\hline 2 & $\begin{array}{l}\text { Is the management of BCa patients on general wards the reason for a lower patient satisfaction } \\
\text { compared to other cancer types? }\end{array}$ \\
\hline 3 & $\begin{array}{l}\text { In patients with high-risk NMIBC, does a higher frequency of cystoscopy follow-up improve the } \\
\text { cost-benefit ratio of recurrence, progression and health-related quality of life? }\end{array}$ \\
\hline 4 & $\begin{array}{l}\text { In low-risk NMIBC what is the optimal surveillance strategy to increase patient satisfaction and } \\
\text { clinical outcomes? }\end{array}$ \\
\hline 5 & $\begin{array}{l}\text { Of patients who are diagnosed with BCa in non-specialised units or general wards, what } \\
\text { proportion have timely uro-oncology input? }\end{array}$ \\
\hline 6 & $\begin{array}{l}\text { In high-risk NMIBC, could frequency of cystoscopy follow-up be substituted with urinary tests to } \\
\text { improve patient acceptability and reduce costs without increasing risk of progression? }\end{array}$ \\
\hline 7 & $\begin{array}{l}\text { Is radiological follow-up as effective as clinical review to detect disease progression following } \\
\text { radical cystectomy/radiotherapy for MIBC? }\end{array}$ \\
\hline 8 & $\begin{array}{l}\text { What PET imaging agent/tracer would increase the sensitivity and specificity of metastatic BCa } \\
\text { detection? }\end{array}$ \\
\hline 9 & $\begin{array}{l}\text { Can new validated technologies improve the detection of metastatic disease in regional } \\
\text { lymphatics and distant sites? }\end{array}$ \\
\hline 10 & $\begin{array}{l}\text { Can new urinary and/or serum-based markers improve the detection of BCa reoccurrence post } \\
\text { treatment and/or detection of metastatic BCa? }\end{array}$ \\
\hline 11 & $\begin{array}{l}\text { Can new urinary and/or serum-based markers replace invasive techniques in the diagnosis of } \\
\text { BCa? }\end{array}$ \\
\hline 12 & Following definitive treatment for MIBC what the optimal strategy for surveillance is? \\
\hline 13 & $\begin{array}{l}\text { Would a comorbidity index developed for the assessment of BCa patients better indicate } \\
\text { clinical/cancer outcomes in MIBC compared to the current tools e.g. CCI? }\end{array}$ \\
\hline 14 & Is screening for BCa required in at-risk populations? \\
\hline 15 & $\begin{array}{l}\text { Which biomarkers would allow us to better select high-risk NMBC patients for early } \\
\text { cystectomy? }\end{array}$ \\
\hline 16 & $\begin{array}{l}\text { Could predictive biomarkers improve outcomes in advanced } \mathrm{BCa} \text {, and particularly in } \\
\text { neoadjuvant therapy? }\end{array}$ \\
\hline 17 & $\begin{array}{l}\text { Could molecular profiling of MIBC help select and stratify patients for treatments in respect to } \\
\text { risk of relapse and/or prognosis? }\end{array}$ \\
\hline 18 & $\begin{array}{l}\text { Which prognostic biomarkers are useful in patients with high-risk MIBC and NMIBC to select } \\
\text { effective radical treatments? }\end{array}$ \\
\hline 19 & Can new genomic markers help us risk stratify patients and predict response to therapies? \\
\hline 20 & Is systemic immunotherapy equally effective in all stages of $\mathrm{BCa}$ ? \\
\hline 21 & $\begin{array}{l}\text { Does robotic technology in surgery improve overall survival, clinical outcomes and quality of life } \\
\text { compared to standard techniques in MIBC? }\end{array}$ \\
\hline 22 & $\begin{array}{l}\text { Is organ-preserving radical cystectomy in females both oncologically safe and improves quality } \\
\text { of life? }\end{array}$ \\
\hline
\end{tabular}




\begin{tabular}{|c|c|}
\hline 23 & $\begin{array}{l}\text { In patients with high grade NMIBC, does Mitomycin-C delivered by EMDA cause more serious } \\
\text { adverse events compared to intravesicle BCG? }\end{array}$ \\
\hline 24 & $\begin{array}{l}\text { In patients with NMIBC, does EMDA delivered mitomycin-C, increase effectiveness compared to } \\
\text { postoperative BCG? }\end{array}$ \\
\hline 25 & $\begin{array}{l}\text { In patients with } \mathrm{CIS} \text { and concurrent pT1 urothelial carcinoma, does EMDA Mitomycin-C increase } \\
\text { the time to recurrence compared to postoperative BCG? }\end{array}$ \\
\hline 26 & $\begin{array}{l}\text { In patients with NMIBC, does single-dose, preoperative EMDA mitomycin-C increase time to } \\
\text { recurrence and reduce the number of adverse events compared to a single-dose, postoperative } \\
\text { mitomycin-C and/or transurethral resection of bladder tumor alone? }\end{array}$ \\
\hline 27 & $\begin{array}{l}\text { Does the administration of alvimopan as part of an ERP (up to } 15 \text { doses over seven days) reduce } \\
\text { the time to tolerance of solid food, discharge and rate of major adverse events, in patients } \\
\text { undergoing radical cystectomy and urinary diversion? }\end{array}$ \\
\hline 28 & Is intravesical gemcitabine effective in treating BCG-refractory patients with NMBIC? \\
\hline 29 & What is the optimal benefit:risk urine concentration of gemcitabine? \\
\hline 30 & What is the optimal strain, dose and schedule for intravesical BCG in NMIBC? \\
\hline 31 & $\begin{array}{l}\text { In patients who receive neoadjuvant chemotherapy treatment, are survival benefits associated } \\
\text { with low grade toxicity and better quality of life? }\end{array}$ \\
\hline 32 & $\begin{array}{l}\text { What is the impact of socioeconomic status and demographic characteristics on diagnostic and } \\
\text { treatment pathway? }\end{array}$ \\
\hline 33 & $\begin{array}{l}\text { Should investigation for haematuria and subsequent TURBT be prioritized based on urinary } \\
\text { biomarkers? }\end{array}$ \\
\hline 34 & $\begin{array}{l}\text { Would improvement in surgical techniques for TURBT lead to improvement in clinical } \\
\text { outcomes? }\end{array}$ \\
\hline 35 & What are the barriers for the use of single shot mitomycin-C? \\
\hline 36 & $\begin{array}{l}\text { What is the role of chemotherapy in adjuvant therapy alone and/or in combination with } \\
\text { immunotherapy? }\end{array}$ \\
\hline 37 & $\begin{array}{l}\text { In NMIBC, would agents for adjuvant intravesical therapy (either single shot or course) be } \\
\text { associated with better clinical outcomes and improved side effects? }\end{array}$ \\
\hline 38 & Can immune checkpoint inhibitors replace chemotherapy in the neoadjuvant setting? \\
\hline 39 & $\begin{array}{l}\text { Is there a role for immune checkpoint inhibitors in combination with chemotherapy in the } \\
\text { neoadjuvant setting, particularly in advanced } \mathrm{BCa} \text { ? }\end{array}$ \\
\hline 40 & Is systemic drug sequencing superior to combination therapies in advanced $\mathrm{BCa}$ ? \\
\hline 41 & $\begin{array}{l}\text { What is the role of chemotherapy alone in advanced } \mathrm{BCa} \text { and what is the optimum } \\
\text { chemotherapy/ immune checkpoint inhibitors sequence? }\end{array}$ \\
\hline
\end{tabular}

\begin{tabular}{|c|c|}
\hline \multicolumn{2}{|l|}{ Round 2} \\
\hline Number & Additional unanswered research questions \\
\hline 1 & $\begin{array}{l}\text { How patients would find suitable and feasible to measure patients experience through the } \\
\text { different pathways? }\end{array}$ \\
\hline 2 & $\begin{array}{l}\text { Are the long-term side effects of treatment explained sufficiently and understandably to } \\
\text { patients during the treatment decision making phase? }\end{array}$ \\
\hline 3 & Is the BCa pathway diagnosis well understood? example, the significance of haematuria? \\
\hline 4 & What is the consequence of delay between TURBT and definitive treatment? \\
\hline
\end{tabular}




\begin{tabular}{|l|l|}
\hline 5 & What is the quality of life for patients having hyperthermia Mitomycin C? \\
\hline 6 & $\begin{array}{l}\text { How should bladder cancer in-situ (CIS) be managed in light of a reduced international supply of } \\
\text { BCG? }\end{array}$ \\
\hline 7 & $\begin{array}{l}\text { Would removing TURBT as an allowed 'first definitive treatment' for muscle invasive bladder } \\
\text { cancer make more difference to overall survival than any tweaking of adjuvant or neoadjuvant } \\
\text { strategies? }\end{array}$ \\
\hline 8 & $\begin{array}{l}\text { Do patients get consistent advice and balanced information about options in respect to urinary } \\
\text { diversion? }\end{array}$ \\
\hline 9 & $\begin{array}{l}\text { Is there an optimum CNS:Pt ratio to ensure optimum support for patients and families affected } \\
\text { by Bladder Cancer? }\end{array}$ \\
\hline
\end{tabular}


Table S2. Lay version of the unanswered research questions used in the $\mathbf{1}^{\text {st }}$ and $2^{\text {nd }}$ round of survey for patients.

\begin{tabular}{|c|c|}
\hline Number & Unanswered research question \\
\hline \multicolumn{2}{|l|}{ Round 1} \\
\hline 1 & $\begin{array}{l}\text { Would patient satisfaction significantly increase if the investigations and treatments were less } \\
\text { invasive and follow up was required less often? }\end{array}$ \\
\hline 2 & $\begin{array}{l}\text { If patients with bladder cancer were treated on specialist hospital wards, would their level of } \\
\text { satisfaction increase? }\end{array}$ \\
\hline 3 & $\begin{array}{l}\text { In people with high-risk bladder cancer, would more regular follow-up using cystoscopy } \\
\text { increase the identification of cancer progression and quality of life without increasing costs? }\end{array}$ \\
\hline 4 & $\begin{array}{l}\text { In patients with low-risk bladder cancer what would be an acceptable surveillance strategy to } \\
\text { both increase patient satisfaction and reduce side effects without compromising cancer } \\
\text { control? }\end{array}$ \\
\hline 5 & $\begin{array}{l}\text { How many people diagnosed with bladder cancer on general hospital wards are reviewed by an } \\
\text { oncologist specialising in urology cancer? }\end{array}$ \\
\hline 6 & $\begin{array}{l}\text { In high-risk bladder cancer patients, if urinary tests were available as an alternative to current } \\
\text { follow-up, would this help to increase patient satisfaction? }\end{array}$ \\
\hline 7 & $\begin{array}{l}\text { When patients are treated with cystectomy (bladder removal) or radiotherapy, is progression of } \\
\text { their cancer easier to detect using scans or by carrying out a review of their symptoms? }\end{array}$ \\
\hline 8 & $\begin{array}{l}\text { What is the best drug that can be given prior to a scan to increase the detection rate of bladder } \\
\text { cancers that have spread to other organs (metastasis)? }\end{array}$ \\
\hline 9 & $\begin{array}{l}\text { Can new technologies improve the detection of the spread of bladder cancer (metastasis) to } \\
\text { other parts of the body? }\end{array}$ \\
\hline 10 & $\begin{array}{l}\text { Could new urine or blood tests for bladder cancer increase the number of patients picked up } \\
\text { with cancer recurrance following treatment, and/or the spread of cancer(metastasis) to other } \\
\text { parts of the body? }\end{array}$ \\
\hline 11 & Can new urine or blood tests improve the diagnosis of bladder cancer? \\
\hline 12 & $\begin{array}{l}\text { How should patients with high-risk cancer be monitored after their cancer treatment to ensure } \\
\text { that any return of the cancer is found? }\end{array}$ \\
\hline 13 & $\begin{array}{l}\text { Would a scoring system, specifically developed for bladder cancer patients, help clinicians in } \\
\text { predicting cancer outcomes for patients with high-risk cancer? }\end{array}$ \\
\hline 14 & Is screening for bladder cancer required in those people at risk of bladder cancer? \\
\hline 15 & $\begin{array}{l}\text { Which markers (found in blood, tissue or other bodily fluids - which are related to the cancer) } \\
\text { would allow doctors to better select patients for early cystectomy (bladder removal)? }\end{array}$ \\
\hline 16 & $\begin{array}{l}\text { Could the identification of certain markers (found in the blood, urine or tissue which are related } \\
\text { to the cancer) improve outcomes in advanced bladder cancer, especially in patients who } \\
\text { require chemotherapy or radiotherapy prior to surgery for their bladder cancer? }\end{array}$ \\
\hline 17 & $\begin{array}{l}\text { Could the identification of the important molecules and genes present in high-risk bladder } \\
\text { cancer help to ensure that patients are offered the right treatment to ensure the best possible } \\
\text { cancer outcome/prognosis? }\end{array}$ \\
\hline 18 & $\begin{array}{l}\text { Which markers (found in blood, tissue or other fluids - which are related to the cancer) are } \\
\text { useful to select more effective treatments in patients with high-risk bladder cancer }\end{array}$ \\
\hline 19 & $\begin{array}{l}\text { Can new genetic markers help us identify which patients require which treatment (risk } \\
\text { stratification) and how they will respond to treatment? }\end{array}$ \\
\hline 20 & $\begin{array}{l}\text { Is immunotherapy (a treatment that helps your immune system fight the cancer) equally } \\
\text { effective in all stages of bladder cancer? }\end{array}$ \\
\hline 21 & $\begin{array}{l}\text { Can cystectomy (removal of the bladder) using robot assistance improve survival rates and } \\
\text { quality of life and decrease the risk of the cancer reoccurring compared to standard surgery } \\
\text { techniques? }\end{array}$ \\
\hline
\end{tabular}




\begin{tabular}{|c|c|}
\hline 22 & $\begin{array}{l}\text { Is it safe to carry out surgery to remove the bladder (leaving the reproductive organs behind e.g } \\
\text { ovaries) in women or is it more likely to lead to cancer reoccurring? }\end{array}$ \\
\hline 23 & $\begin{array}{l}\text { In patients with high grade bladder cancer, does the use of an electrical current (EMDA) to send } \\
\text { the concentrated chemotherapy treatment to the bladder tissue cause more serious adverse } \\
\text { events compared to Bacillus Calmette-Guérin (BCG) which is an antiviral treatment)? }\end{array}$ \\
\hline 24 & $\begin{array}{l}\text { In patients with low-risk bladder cancer, is treatment with the use of an electrical current } \\
\text { (EMDA) plus Mitomycon-C (chemotherapy) more effective than postoperative Bacillus } \\
\text { Calmette-Guérin (BCG - antiviral treatment)? }\end{array}$ \\
\hline 25 & $\begin{array}{l}\text { In patients with early bladder and urothelial cancer, does the use of an electrical current } \\
\text { (EMDA) plus Mitomycon-C (chemotherapy) increase the time between treatment and } \\
\text { recurrence of cancer compared to Bacillus Calmette-Guérin (BCG- antiviral treatment)? }\end{array}$ \\
\hline 26 & $\begin{array}{l}\text { Does a single-dose electrical current (EMDA) plus Mitomycon-C (chemotherapy) increase the } \\
\text { time to cancer reoccurrence and reduce the number of serious adverse events (e.g. blood } \\
\text { infection/sepsis), compared to a single dose of Mitomycin-C and/or compared to undergoing a } \\
\text { surgical bladder tumour removal? }\end{array}$ \\
\hline 27 & $\begin{array}{l}\text { Does the administration of alvimopan (a type of pain killer) as part of an enhanced recovery } \\
\text { programme reduce the time it takes for patients to tolerate solid foods, be discharged and/or } \\
\text { the number of major adverse events (e.g. bowel obstruction), in patients undergoing removal } \\
\text { of the bladder? }\end{array}$ \\
\hline 28 & $\begin{array}{l}\text { Does gemcitabine (chemotherapy) given into the bladder prevent or delay the cancer } \\
\text { progressing in patients previously treated with Bacillus Calmette-Guérin (BCG - antiviral } \\
\text { treatment) but who are not responding anymore? }\end{array}$ \\
\hline 29 & $\begin{array}{l}\text { What is the quantity of gemcitabine (chemotherapy) in the urine that will provide the best } \\
\text { balance between benefit and risk? }\end{array}$ \\
\hline 30 & $\begin{array}{l}\text { What is the optimal type, dose, and schedule for administrating Bacillus Calmette-Guérin (BCG } \\
\text { - antiviral treatment) to patients with low-risk bladder cancer? }\end{array}$ \\
\hline 31 & $\begin{array}{l}\text { In patients who receive chemotherapy prior to their surgery, is low rate of side effects and } \\
\text { better quality of life associated with a higher survival rate? }\end{array}$ \\
\hline 32 & $\begin{array}{l}\text { What is the impact of socioeconomic status (i.e. work, income) and demographic characteristics } \\
\text { (e.g. age, sex) on diagnosis and treatment pathways? }\end{array}$ \\
\hline 33 & $\begin{array}{l}\text { Should investigation for blood in the urine and subsequent surgical bladder tumor removal be } \\
\text { prioritized based on urinary markers? }\end{array}$ \\
\hline 34 & $\begin{array}{l}\text { Would improvement in surgical techniques for bladder tumor removal lead to improvement in } \\
\text { clinical outcomes? }\end{array}$ \\
\hline 35 & $\begin{array}{l}\text { What are the barriers for the use of single shot of mitomycin-C (Chemotherapy into the } \\
\text { bladder)? }\end{array}$ \\
\hline 36 & $\begin{array}{l}\text { What is the role of chemotherapy as an additional treatment to surgery and/or in combination } \\
\text { with immunotherapy (a drug that helps your immune system fight the cancer)? }\end{array}$ \\
\hline 37 & $\begin{array}{l}\text { In low-risk bladder cancer, would the administration of medicines directly into the bladder } \\
\text { (whether a single shot or course) be associated with better outcomes and improved side } \\
\text { effects? }\end{array}$ \\
\hline 38 & Can the use of immunotherapy replace chemotherapy prior to surgery? \\
\hline 39 & $\begin{array}{l}\text { Is there a benefit to combining immunotherapy with bladder chemotherapy prior to surgery, } \\
\text { particularly in advanced bladder cancer? }\end{array}$ \\
\hline 40 & $\begin{array}{l}\text { Are drug treatments given in sequence (one after the other) superior to combinations of } \\
\text { treatments given at one time in advanced bladder cancer? }\end{array}$ \\
\hline 41 & $\begin{array}{l}\text { In advanced bladder cancer what is the role of bladder chemotherapy given alone and what is } \\
\text { best chemotherapy/immunotherapy sequence? }\end{array}$ \\
\hline
\end{tabular}

Round 2

Number Additional unanswered research questions 


\begin{tabular}{|l|l|}
\hline 1 & $\begin{array}{l}\text { How patients would find suitable and feasible to measure patients experience through the } \\
\text { different pathways? }\end{array}$ \\
\hline 2 & $\begin{array}{l}\text { Are the long-term side effects of treatment explained sufficiently and understandably to } \\
\text { patients during the treatment decision making phase? }\end{array}$ \\
\hline 3 & $\begin{array}{l}\text { Is the bladder cancer pathway diagnosis well understood? example, the significance of blood in } \\
\text { the urine? }\end{array}$ \\
\hline 4 & $\begin{array}{l}\text { What is the consequence of delay between the time of surgical bladder tumour removal and } \\
\text { definitive treatment? }\end{array}$ \\
\hline 5 & $\begin{array}{l}\text { What is the quality of life for patients having hyperthermia Mitomycin C? } \\
\text { BCw should bladder cancer in-situ be managed in light of a reduced international supply of }\end{array}$ \\
\hline 6 & $\begin{array}{l}\text { If surgical removal of bladder tumours was reclassified as a diagnostic test for bladder cancer } \\
\text { rather than a treatment, would the national cancer target to deliver a cancer treatment within } \\
31 \text { days of diagnosis e.g. radiotherapy, chemotherapy or bladder removal (cystectomy) increase } \\
\text { patient survival rates? }\end{array}$ \\
\hline 8 & $\begin{array}{l}\text { Do patients get consistent advice and balanced information about options in respect to urinary } \\
\text { diversion? }\end{array}$ \\
\hline 9 & $\begin{array}{l}\text { Is there an optimum CNS:Pt ratio to ensure optimum support for patients and families affected } \\
\text { by bladder cancer? }\end{array}$ \\
\hline
\end{tabular}

